\section{A booster course in immunization}

\author{
KATHLEEN A. KUK
}

The public's image of immunization needs a shot in the arm. Although many view immunization as a rite of passage in infancy and childhood, it is actually a practice that, in many cases, must be repeated throughout one's lifetime. Although immunization was eagerly embraced in the 1950 s and 1960 s as a means of ending dread pandemics, it is now spurned by some parents who misguidedly fear its adverse effects. Although many assume that diseases like polio, diphtheria, German measles, and smallpox have been wiped off the globe due to immunization, only the latter disease holds that enviable position. All other diseases are in danger of increasing if parents fail to immunize their children.

Thus, the ranks of the unimmunized continue to swell. It includes unvaccinated infants, young adults who are unaware that the immunizations they received in their youth may be ineffective, adults who have let their protective status lapse by failing to get booster shots, and the elderly and infirm who have not taken advantage of new advances in immunization.

A glance through the following list may point out the gaps in one's own immunization profile.

\section{Diphtheria}

Diphtheria is a bacterial infection that most commonly affects the respiratory membranes, causing sore throat, chills, nausea, and nasal discharge. The bacteria can also infiltrate open wounds and cause skin lesions. Diphtheria is also a potentially lethal disease that will claim the life of 1 in 10 victims - often due to heart failure or obstructed breathing.

\section{Pertussis}

Pertussis (whooping cough) is a highly communicable bacterial disease that causes severe bouts of coughing which interfere with eating, drinking, and breathing. It can strike all ages, but threequarters of the cases in the United States occur in children under 5 years of age. And the younger the child, the more serious the disease. More than half the children under 1 year of age are hospitalized with such complications as pneumonia or convulsions.

\section{Tetanus}

Tetanus (lockjaw) is a neurologic disease that occurs when bacteria enter the body through a contaminated wound. Once it has gained entry, the bacteria spawn poisons that cause severe muscle spasms in the jaw, neck, arms, legs, and chest. Four of every ten persons who get tetanus die when the rigid contractions interfere with breathing.

\section{DTP vaccine}

Diphtheria, tetanus, and pertussis were once common diseases that caused a great number of deaths in the United States. The three illnesses have since lent their initials to the combination vaccine that has drastically reduced the incidence of all three diseases. Today, only about 10 cases of diphtheria, 75 cases of tetanus, and 1,700 cases of pertussis occur annually. Virtually all the victims share one common trait-they have never been or were insufficiently immunized.

The U.S. Public Health Service and the American Academy of Pediatrics recommend that every child receive at least three doses of the DTP vaccine during the first year of life, a fourth dose at about 18 months of age, and a booster shot between the fourth and seventh birthdays.

Unfortunately, a number of parents are refusing to immunize their children because they fear that a rare reaction to the vaccine will leave permanent brain damage. Health officials argue that although 
soreness, swelling, and a slight fever are common reactions to the shot, a temperature of $105 \mathrm{~F}$. follows only 1 of 330 DTP shots, unusual highpitched crying in 1 of 900 shots, convulsions after 1 in every 1,750 shots, severe brain problems in 1 of 110,000 shots, and permanent brain damage in 1 of 310,000 shots.

Proponents of the DTP vaccine are also quick to point out that not being immunized poses a greater threat to the child's health. For example, 22 of every 1,000 children who develop pertussis will suffer convulsions or more serious disorders of the brain.

To minimize the already slight risk of an adverse reaction to the DTP vaccine, physicians are advised not to give the shot to any child who:

- has an illness or fever at the time of the scheduled appointment.

- has a history of convulsions or other problem of the nervous system.

- is undergoing treatment or drug therapy that lowers the body's ability to fight infection.

- has had a reaction to a previous DTP shot, such as: a fever of $105 \mathrm{~F}$. or greater; an episode of limpness or paleness; prolonged, continuous crying sessions; a high-pitched cry; or convulsions.

It should be pointed out that the responsibilities of immunization do not end at childhood. Booster shots of tetanus and diphtheria are recommended every ten years. (Pertussis protection is no longer required in children over 7 years of age because the disease is neither common nor very severe in this age group.) Yet random blood surveys reveal that half the adult population lacks protective levels of tetanus and diphtheria antibodies-leaving themselves at serious risk of illness and even death.

For this reason, it is especially important that all wounds receive prompt attention. Although deep puncture wounds contaminated with dirt or saliva are most likely to promote the growth of the tetanus bacteria, the disease can also be transmitted through supposedly "minor" injuries, animal bites, burns, frostbite, or surgery. The best treatment is a thorough cleansing of the wound, with a booster shot administered if the vaccine has not been given in the previous 5 years.

\section{Measles}

Measles is a serious childhood ailment that causes a rash, high fever, runny nose, cough, and watery eyes. Less-fortunate victims develop ear infections or pneumonia ( 1 in 10), inflammation of the brain leading to deafness, convulsions, or mental retardation $(1$ in 1,000), or even death ( 2 in 10,000).

\section{Mumps}

Mumps, another common disease of childhood, causes fever, headache, and distinctive swelling of the salivary glands. More serious but rarer complications include meningitis, encephalitis, and deafness.

\section{Rubella}

Rubella (German measles) is a rather mild disease that produces a slight fever, rash, or swollen glands in the neck. It could be dismissed as a tiresome nuisance were it not for its disastrous effect upon the unborn. Women who are exposed to the virus during the first three months of pregnancy are likely to give birth to babies that have heart defects, mental retardation, deafness, or blindness.

\section{MMR vaccine}

The aforementioned diseases are championed by yet another triad of protection-the MMR vaccine. The vaccine can be administered all at once, or the individual components can be given separately or in combination. Because MMR is not as effective during the earliest months of birth, the shot(s) should be delayed until 15 months of age. Unlike DTP, the vaccine needs only be administered once to provide lifetime immunity.

Pockets of vulnerability remain, however. At present, 10 to 15 percent of young adults are 
susceptible to rubella because they have never received the vaccine nor been naturally exposed to the virus. It is therefore strongly urged that the rubella portion of the vaccine be administered to all women of child-bearing age who do not have documented proof of vaccination.

Measles presents a more confusing scenario. At least 20 percent of young adults are prey to measles not because they were never immunized...but because they received inadequate immunization. Many received their measles shot before their first birthday. Others received a "killed" vaccine that is less potent than the currently available "live" vaccine. Therefore, anyone who is unsure of their immunization status should be revaccinated, particularly if they were originally vaccinated between 1963 and 1967. Folks born before 1957 need not bother; if they emerged unscathed from the epidemics that raged in pre-vaccination days, they have probably acquired natural immunity.

Nearly 10 percent of young adults also remain vulnerable to mumps. Persons who were vaccinated with the killed virus between 1950 and 1978 may wish to be revaccinated. Men, especially, should heed this advice. One in four adolescent and adult males who succumb to mumps will also develop a painful inflammation of the testicles. In rare cases, this may result in permanent sterility.

\section{Poliomyelitis}

Polio is a viral infection that may progress to paralysis and sometimes death. Although it has been virtually eliminated in the U.S. since the introduction of the vaccine in the mid-50s, the disease continues to be a scourge in other parts of the world.

The vaccine is available in two very effective forms: the Sabin or live oral polio vaccine (OPV), and the Salk or inactivated injectable polio vaccine (IPV). Either version must be repeated in several doses to provide the best protection.

Polio vaccines are not known to cause any side effects other than local pain and redness. Only very rarely (once in 8.1 million cases) does the polio vaccine trigger the actual paralytic disease. A more likely danger is that live polio viruses shed by the immunized infant may infect a household member whose own immune system is impaired. As a precaution, the inactivated injectable vaccine is administered in such situations.

\section{Influenza}

For most Americans, the flu bug is the annual bearer of chills, fever, body ache, and nausea. But for thousands of other individuals - particularly adults and children who have long-term heart and lung problems, or elderly residents of nursing homes and other chronic-care facilities - an influenza outbreak means hospitalization and possibly death.

Others at moderate risk of influenza-related complications include:

- Otherwise healthy individuals over 65 years of age.

- People with chronic diseases, such as kidney disease, anemia, diabetes, asthma, or cystic fibrosis.

- People who have an immunosuppressive illness or who are receiving medical treatment that impairs their immune system.

- Children who are receiving long-term aspirin therapy, which puts them at increased risk of Reye's syndrome following a bout of flu.

- Caregivers of all such high-risk individuals.

A single flu shot given at the start of each November-to-April flu season will provide annual protection to most (but not all) recipients.

However, the routine must be repeated each year because subtle shifts in the viral strains make last year's vaccine model obsolete.

Influenza vaccine is made of inactivated virus that will not initiate the illness itself. However, soreness at the injection site and/or a slight fever may persist for one to two days. Unlike the vaccine used in the 1976 swine flu campaign, recent vaccinations have not been linked to paralytic illnesses.

\section{Pneumococcal infections}

Roughly 75 to 285 persons in a crowd of 100,000 will fall victim each year to pneumococcal infections including bacteremia, meningitis, and pneumonia. Fortunately, a vaccine against the most virulent strain of Streptococcus pneumonia was developed in 1977. Targeted high-risk groups include all candidates of the influenza vaccine, as well as persons who have impaired spleen function due to surgical removal or radiation therapy, or sickle cell anemia.

Unlike the flu shots, the pneumococcal vaccine should only be given once in a person's lifetime. The pneumococcal and influenza vaccines may be given at the same time, but should be given at different sites. Almost half the recipients will experience mild reactions such as redness, swelling, and pain at the injection site; fewer than 1 percent of vaccinees will suffer fever, joint pain, and rash. 
Despite the success of the pneumococcal vaccine, only 10 to 15 percent of individuals at high risk have been immunized. The percentage of persons protected against influenza is only slightly better-a mere 20 percent of all high-risk individuals. The problem may be twofold. The desire to acquire immunization must be matched by the ability to distribute the vaccines.

\section{Hepatitis B}

This viral infection of the liver is primarily transmitted by contaminated needles, sexual activity, or the infected mother to the newborn. Immunization against hepatitis B is important not only in preventing acute and chronic illness, but also as a means of drying up the carrier pool. Nearly 200,000 Americans harbor the hepatitis B virus; 5 to 10 percent will become chronic carriers who unknowingly transmit the virus on to others. Every year, about 50,000 persons with hepatitis will become jaundiced, 4,000 will die of hepatitis Brelated cirrhosis, and 800 will fall to liver cancer.

The population at large has a 5 percent risk of acquiring hepatitis $\mathrm{B}$. However, certain subgroups are at increased risk. Those who should receive the series of three intramuscular injections include:

- Homosexuals

- Intravenous drug abusers

- Recipients of certain blood products

- Hemodialysis patients

- Household and sexual contacts of hepatitis B virus carriers

- Inmates of long-term correctional institutes

- Clients and staff of institutions for the mentally retarded

- Health care workers

The virus itself is derived from the plasma of carriers of the disease. Since the high-risk groups for hepatitis are very similar to that of AIDS, there was concern that the hepatitis vaccine would be contaminated. This theory has been disproved, however. The plasma used to manufacture the hepatitis vaccine undergoes a three-step process that effectively inactivates all known human viruses. The most serious reaction that a recipient will undergo is local soreness, redness, and swelling at the injection site.

\section{Occupational illness}

Certain occupations predispose one to uncommon diseases. Animal handlers and veterinarians might be wise to undergo preventive rabies vaccinations. Likewise, professional globe-trotters will require protection against such exotic illnesses as cholera, typhoid, yellow fever, and the plague. Consult with your personal physician to make sure that theseand the more common immunizations-are provided.

(All material in the Patient Health Guide is reviewed by JAOA referees.)

\section{References}

Adult immunizations. By N.M. Amin. American Family Physician, vol. 33 , pp. $89-104$, Jun 86

Adult immunization: Protocols and problems. By D.S. Fedson. Hospital Practice, vol. 21, pp. 143-155, 158, 15 Jul 86

Influenza and pneumococcal immunization strategies for physicians. By D.S. Fedson. Chest, vol. 91, pp. 436-43, Mar 87

The Merck manual of diagnosis and therapy. Edited by R. Berkow. 14th edition. Merck Sharp \& Dohme Research Laboratories, Rahway, New Jersey, 1982

Recommendations for prevention and control of influenza: Recommendations of the Immunization Practices Advisory Committee. By the Centers for Disease Control, Department of Health and Human Services, Atlanta, Georgia. Annals of Internal Medicine, vol. 105, pp. 399-404, Sep 86

Report of the Committee on Infectious Diseases. 20th edition. American Academy of Pediatrics, Elk Grove Village, Illinois, 1986

\section{For more information}

To obtain further information about immunization against disease, contact your local or state health department, or the following agencies:

The National Foundation for Infectious Diseases

P.O. Box 42022

Washington, D.C. 20015

National Institutes of Allergy and Infectious Diseases

Building 31

Room 7 A32

Bethesda, Maryland 20205
U.S. Department of Health and Human Services

Centers for Disease Control

U.S. Government Printing Office

Department 33

Washington, D.C. 20402

International Association for Medical

Assistance to Travelers

736 Center Street

Lewiston, New York 14092

March of Dimes

1275 Mamaroneck Avenue

White Plains, New York 10605 
For added blood pressure control, a major office-based study shows*...

\section{In the elderly regardless of previous therapy}

\begin{tabular}{l|rcc}
\hline PREVIOUS & \multicolumn{4}{|c}{ Change in BP } \\
\cline { 2 - 4 } ANTIHYPERTENSIVE THERAPY & $\mathrm{n}$ & Systolic & Diastolic \\
\hline Beta blocker (monotherapy) & 1,206 & -22.9 & -12.43 \\
\hline Diuretic (monotherapy) & 820 & -24.2 & -14.4 \\
\hline Free combination & & & \\
: 2 drugs & 2,346 & -17.8 & -10.2 \\
3 drugs & 517 & -17.9 & -9.6 \\
\hline 4 drugs & 142 & -18.7 & -10.8 \\
\hline Fixed combination & 1,621 & -21.97 & -12.6 \\
\hline
\end{tabular}

*TENORETIC Evaluation Program, an open 28-day study of 26,892 hypertensive patients (data on file, Stuart Pharmaceuticals, Wilmington, Delaware); physicians entered those patients needing more control than provided by monotherapy. TENORETIC is not indicated for the initial therapy of hypertension.

tDecreases in blood pressure were statistically significant 


\section{In the elderly without added side effects}

- Total number of older patients treated: 9,098.

Do adverse reactions reported in $89.2 \%$.

- Patients reported feeling either better than or as good as before: $94.7 \%$.
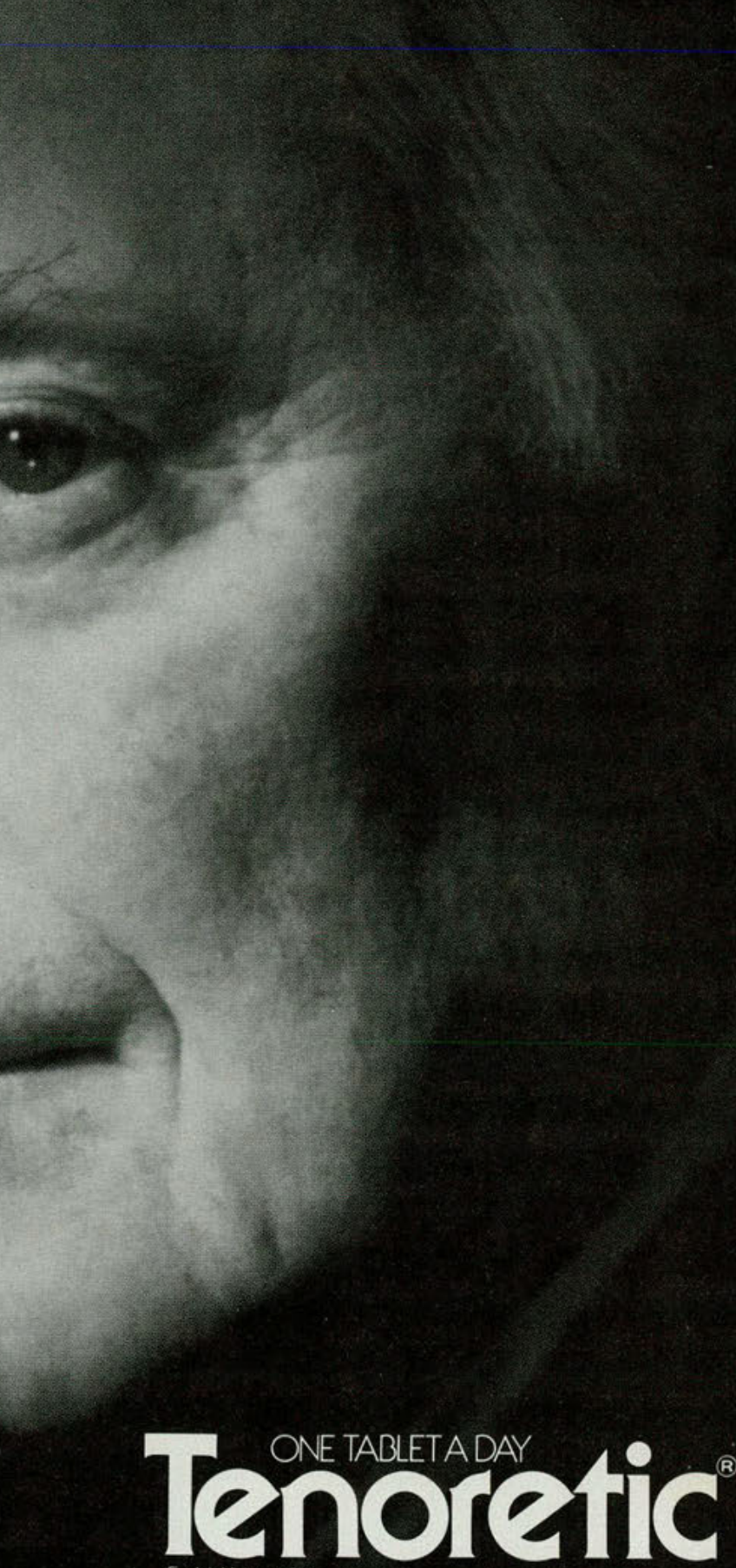

ch tablet contains

TENORMIN* (atenoloi) $50 \mathrm{mg}$ or $100 \mathrm{mg}$ and chlorthalidone $25 \mathrm{mg}$

For added control and convenience ...without added side effects. 


\section{For added blood pressure control... In black males regardless of age*}

\begin{tabular}{cc|cr}
\hline \multirow{2}{*}{ Age } & & \multicolumn{2}{c}{ Change in BPt } \\
\hline \multirow{n}{*40}{} & $\mathrm{n}$ & Systolic & Diastolic \\
\hline $40-60$ & 318 & -18.9 & -14.1 \\
\hline$>60$ & 828 & -20.5 & -13.9 \\
\hline
\end{tabular}

*TENORETIC Evaluation Program, an open 28-day study of 26,892 hypertensive patients (data on file, Stuart Pharmaceuticals, Wilmington, Delaware): physicians entered those patients needing more control than provided by monotherapy.

TENORETIC is not indicated for the initial therapy of hypertension.

tDecreases in blood pressure were statistically significant. 


\section{And in all patients regardless of age, race, sex*}

\begin{tabular}{lc|cc}
\hline \multirow{2}{*}{ Type } & & \multicolumn{2}{|c}{ Change in BPt } \\
\cline { 3 - 4 } & $\mathrm{n}$ & Systolic & Diastolic \\
\hline Overall & 26,892 & -20.99 & -13.1 \\
\hline White & 19,185 & -20.9 & -12.9 \\
\hline Black & 3,701 & -21.2 & -13.5 \\
\hline Other & 1,147 & -22.3 & -13.8 \\
\hline Female & 12,540 & -21.6 & -13.1 \\
\hline Male & 11,844 & -20.3 & -13.1 \\
\hline
\end{tabular}

*TENORETIC Evaluation Program, an open 28-day study of 26,892 hypertensive patients (data on file, Stuart Pharmaceuticals, Wilmington, Delaware): physicians entered those patients needing more control than provided by monotherapy. TENORETIC is not indicated for the initial therapy of hypertension. tDecreases in blood pressure were statistically significant.

Tenoretic Each lablet contains

TENORMIN* (atenolio) $50 \mathrm{mg}$ or $100 \mathrm{mg}$ and chiorthalidone $25 \mathrm{mg}$

For added control and convenience ...without added side effects. 


\section{Tenoretic}

TeNORMIN* (atenolol) $50 \mathrm{mg}$ or $100 \mathrm{mg}$

\section{Added control, added convenience ...without added side effects... regardless of age, race, or sex.}

\section{Please consult complete product information before prescribing. A summary follows:}

TENORETIC (atenolol and chlorthalidone) is for the treatment of hypertension. It combines the antihypertensive activity of two agents: a beta, selective (cardioselective) hydrophilic blocking agen atenolol, TENORMIN) and a monosulionamyl diuretic (chlorthalidone)

AND USAGE: TENORETIC is indicated for the treatment of hypertension. This fixedcose combination drug is not indicated for initial therapy of hypertension. ff the fixed-dose combination represents the dose appropriat

convenient than the separate components. CONTRAINDICATIONS: TENORETIC is contraindicated in patients with: sinus bradycardia, hear
block greater than first degree, cardiogenic shock, overt cardiac failure (see WARNINGS), anuria. block greater than first degree, cardiogenic shock, overt cardiac
hypersensitivity to this product or to sultonamide-derived drugs.

hypersensitivity to this product or to sultonamide-derived drugs.
WARNINGS: Cardlac Fallure: Sympathetic stimulation is necessary in supporting circulatory function in congestive heart failure, and beta blockade carries the potential hazard of further depressing myocardial contractility and precipitating more severe failure. In hypertensive patients who have congestive heart failure controlled by digitalis and diuretics. TENORETIC should be idministered cautiously. Both digitalis and atenolol slow AV conduction.

In Patients Without a History of Cardlac Fallure: Continued depression of the myocardium with beta-blocking agents over a period of time can, in some cases, lead to cardiac failure. At the first sign of impending cardiac failure, patients receiving TENORETIC should be digitalized and/or be given additional diuretic therapy. Observe the patient closely. If cardiac failure continues despite

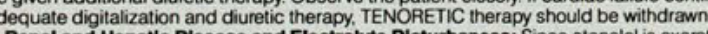

Renal and Hepatic Disease and Electrolyte Disturbances: Since atenolol is excreted via the NORETIC should be used with caution in patients with impaired renal function

In patients with renal disease, thiazides may precipitate azotemia. Since curnulative effects may develop in the presence of impaired ren
TENORETIC should be discontinued.

In patients with impaired hepatic function or progressive liver disease, minor alterations in fluid and In patients with impaired hepatic function or progressive liver disease, minor alterations in fluid and
electrolyte balance may precipitate hepatic coma. TENORETIC should be used with caution in these patients.

Ischemic Heart Disease: Although not yet reported with atenolol following abrupt cessation of therapy with certain beta-blocking agents in patients with coronary artery disease, exacerbations angina pectoris and, in some cases, myocardial infarction have been reported. Therefore, such patients should be cautioned against interruption of therapy without the physician's advice. Even in the absence of overt angina pectoris, when discontinuation of TENORETIC is planned, the patien should be carefully observed and should be advised to limit physical activity to a minimum.

stated if withdrawal symptoms occur

Bronchospastic Diseases: PATIENTS WITH BRONCHOSPASTIC DISEASE SHOULD, IN GENERAL, NOT RECEIVE BETA BLOCKERS. Because of its relative beta, -selectlvity, howev TENORETIC may be used with caution in patients with bronchospastic disease who do not respond to, or cannot tolerate, other antihypertensive treatment. Since beta,- selectivity is not absolute, the lowest possible dose of TENORETIC should be used and a beta - -stimulating agent (bronchodllator) should be made avallable. If dosage must be increat

Anesthesia and Major Surgery: As with all beta-receptor blocking drugs, it may be decided to Anesthesia and Major Surgery: As with all beta-receplor blocking drugs, it may be decided to
withdraw TENORETIC belore surgery. In this case, 48 hours should be allowed to elapse between last dose and anesthesia. If treatment is continued, care should be take

agents because of the risk of further depression of the myocardium. Beta blockers are competitive inhibitors of beta-receptor agonists and their effects on the heart be reversed by administration of such agents; eg. dobutamine or isoproterenol with caution (see section on OVERDOSAGE). Manifestations of excessive v)

hypotabolic and Endocrine Effects: TENORETIC may be used with caution in diabetic patients. Beta blockers may mask tachycardia occurring with hypoglycemia, but other manifestations such as dizziness and sweating may not be significantly affected. Atenolol does not potentiate insulin-induced hypoglycemia an levels.

Insulin requirements in diabetic patients may be increased, decreased, or unchanged; latent diabetes mellitus may become manifest during chlorthalidone administration

Beta-adrenergic blockade may mask certain clinical signs (eg, tachycardia) of hyperthyroidism Abrupt withdrawal of beta blockade might precipitate a thyroid storm; therefore, patients suspected of
developing thyrotoxicosis and from whom TENORETIC therapy is to be withdrawn should be monitored closely

Because calcium excretion is decreased by thiazides. TENORETIC should be discontinued before carrying out tests for parathyroid function. Pathologic changes in the parathyroid glands, with hypercalcemia and hypophosphatemia, have been observed in a few patients on prolonged thiazide therapy: however, the common complications of hyperparathyroidism such as renal fithiasis, bone resorption, and peptic ulceration have not been seen

Hyperuricemia may occur or acute gout may be precipitated in certain patients receiving thiazide

PRECAUTIONS, General-Electrolyte and Fluid Balance Status: Periodic determination of serum electrolytes to detect possible electrolyte imbalance should be performed at appropriate intervals

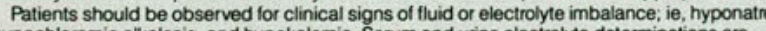
hypochloremic alkalosis, and hypokalemia. Serum and urine electrolyte determinations are particularly important when the patient is vomiting excessively or receiving parenteral fluids. Warning signs or symptoms of fluid and electrolyte imbalance include dryness of the mouth, thirst, weakness, lethargy drowsiness, restiessness. muscle pains or cramps, muscular fatigue, hypotension, oliguria, tachycardia, and gastrointestinal disturbances such as nausea and vomiting.

Hypokalemia may develop, especially with brisk diuresis, when severe cirrinosis is present, or during concomitant use of corticosteroids or ACTH

Interference with adequate oral electrolyte intake will also contribute to hypokalemia. Hypokalemia can sensitize or exaggerate the response of the heart to the toxic effects of digitalis (eg, increased ventricular irritability). Hypokalemia may be avoided or treated by use of potassium supplements or foods with a high potassium conten

Any chloride deficit during thiazide therapy is generally mild and usually does not require specific treatment except under extraordinary circumstances (as in liver disease or renal disease). Dilutional hyponatremia may occur in edematous patients in hot weather; appropriate therapy is water restriction rather than administration of salt except in rare instances when the hyponatremia is life-threatening. In actual salt depletion, appropriate replacement is the therapy of choice.

Drug Interactions: TENORETIC may potentiate the action of other antihypertensive agents used concomitantly. Patients treated with TENORETIC plus a catecholamine depletor (eg, reserpine) should be closely observed for evidence of hypotension and/or marked bradycardia which may produce vertigo, syncope, or postural hypotension.

Thiazides may decrease arterial responsiveness to norepinephrine. This diminution is not sufficient to preclude the therapeutic effectiveness of norepinephrine. Thiazides may increase the responsiveness to tubocurarine.
Lithium generally should not be given with diuretics because they reduce its renal clearance and add a high risk of lithium toxicity. Read circulars for lithium preparations before use of such

preparations with TENORETIC.

Should it be decided to discontinue therapy in patients receiving TENORETIC and clonidine concurrently, the TENORETIC should be discontinued several days before the gradual withdrawal of clonidine

Other Precautlons: In patients receiving thiazides, sensitivity reactions may occur with or without a history of allergy or bronchial asthma. The possible exacerbation or activation of systemic lupus erythematosus has been reported. The antihypertensive effects of thiazides may be enhanced in the postsympathectomy patient. Carcinogenesis, Mutagenesis, Impairment of Fertility: Two long-term (maximum dosing duration
of 18 or 24 months) rat studies and one long-term (maximum dosing duration of 18 months) mouse study with atenolol, each employing dose levels as high as $300 \mathrm{mg} / \mathrm{kg} /$ day or 150 times the maximur recommended human dose, did not indicate a carcinogenic potential in rodents.

Atenolol was negative in the mouse dominant lethal test, the Chinese hamster in vivo cytogenetic test and the Salmonella typhimurium back mutation test (Ames test), with or without metabolic activation.

Fertility of male or fernale rats (evaluated at dose levels as high as $200 \mathrm{mg} / \mathrm{kg} /$ day or 100 times the maximum recommended human dose) was unaffected by atenolol administration.

Use in Pregnancy: Pregnancy Category C. TENORETIC (atenolol and chlorthalidone) was studied for teratogenic potential in the rat and rabbit. Doses of 10,100 and $300 \mathrm{mg} / \mathrm{kg} /$ day were administered orally to pregnant rats, with no teratologic effects observed. Two studies were conducted in rabbits in the first study, pregnant rabbits were dosed with 10,100 or $200 \mathrm{mg} / \mathrm{kg} /$ day. No teratologic changes were noted; embryonic resorptions were observed at all dose levels (ranging from approximately 5 times to 100 times the maximum recommended human dose). In a second rabbit study, dosages were 5,10 and $25 \mathrm{mg} / \mathrm{kg} /$ day. No teratogenic or embryotoxic effects were demonstrated. It is concluded that the no-eflect level for embryonic resorptions is $25 \mathrm{mg} / \mathrm{kg} /$ day (approximately 12.5 times the only if the potential benefit justifies the potential risk to the fetus.

Atenolol-Atenolol has been shown to produce a dose-related increase in embryo/fetal resorption in rats at doses equal to or greater than $50 \mathrm{mg} / \mathrm{kg}$ or 25 or more times the maximum recommended human dose. Although similar effects were not seen in rabbits, the compound was not evaluated in rabbits at doses above $25 \mathrm{mg} / \mathrm{kg}$ or 12.5 times the maximum

no adequate and well-controlled studies in pregnant women.

chlorthalidone and related drugs in pregnant women requires that the anticipated benefits of the drug be weighed against possible hazards to the fetus. These hazards include fetal or neonatal jaundice. hrombocytopenia, and possibly other adverse reactions which have occurred in the adult Nursing Mothers: It is not established to what extent this drug is excreted in human milk. Since most drugs are excreted in human milk, nursing should not be undertaken by mothers receiving

Pediatric Use: Safety and effectiveness in children have not been established.

ADVERSE REACTIONS: TENORETIC is usually well tolerated in properly selected patients. Most adverse effects have been mild and transient. The adverse effects observed for TENORETIC are essentially the same as those seen with the individual components

Atenolol: The frequency estimates that follow derive from controlled studies in which adverse reactions were either volunteered by the patient (US studies) or elicited, eg, by checklist (foreign studies). The reported frequency of elicited adverse effects was higher for both atenolol and placebotreated patients than when these reactions were volunteered. Where frequency of adverse effects for atenolol and placebo is similar, causal relationship to atenolol is uncertain

The data present these estimates in terms of percentages: first from the US studies (volunteered side effects) and then from both US and foreign studies (volunteered and elicited side effects)
US STUDIES (\% ATENOLOL-\% PLACEBO):

CARDIOVASCULAR: bradycardia (3\%-0\%), cold extremities (0\%-0.5\%), postural hypotension $(2 \%-1 \%)$, leg pain $(0 \%-0.5 \%$

CENTRAL NERVOUS SYSTEM/NEUROMUSCULAR: dizziness ( $4 \%-1 \%$ ), vertigo (2\%-0.5\%), lightheadedness $(1 \%-0 \%)$, tiredness $(0.6 \%-0.5 \%)$, fatigue $(3 \%-1 \%)$, lethargy $(1 \%-0 \%)$, drowsiness $(0.6 \%-0 \%)$, depression $(0.6 \%-0.5 \%)$, drearning $(0 \%-0 \%)$

\section{RESPIRATORY (See WARNINGS): wheeziness $(0 \%-0 \%)$, dyspnea $(0.6 \%-1 \%)$}

TOTALS US AND FOREIGN STUDIES:

CARDIOVASCULAR: bradycardia (3\%-0\%), cold extremities (12\%-5\%), postural hypotension (4\%-5\%), leg pain $(3 \%-1 \%)$

CENIRAL NERVOUS SYSTEM/NEUROMUSCULAR: dizziness (13\%-6\%), vertigo $(2 \%-0.2 \%)$, lightheadedness $(3 \%-0.7 \%)$, tiredness $(26 \%-13 \%)$. fatigue
$(2 \%-0.5 \%)$, depression (12\%-9\%), dreaming $(3 \%-1 \%)$

GASTROINTESTINAL: diarmea $(3 \%-2 \%)$, nausea $(3 \%-1 \%)$

RESPIRATORY (see WARNINGS): wheeziness $(3 \%-3 \%)$, dyspnea $(6 \%-4 \%)$

MISCELLANEOUS: There have been reports of skin rashes and/or dry eyes associated with the use of beta-adrenergic blocking drugs. The reported incidence is small and, in most cases, the symptom have cleared when treatment was withdrawn. Discontinuance of the drug should be considered if any such reapy.

Therapy. vomiting, cramping, constipation, jaundice (intrahepatic cholestatic jaundice), pancreatitis; CNS: vertigo, paresthesias, xanthopsia; Hematologic: leukopenia, agranulocytosis, thrombocytopenia aplastic anemia: Hypersensitivity: purpura, photosensitivity, rash, urticaria, necrotizing angitis
(vasculitis, cutaneous vasculitis), Lyell's syndrome (loxic epidermal necrolysis); Miscellaneous: (vasculitis, cutaneous vasculitis), Lyeils syndrome (loxic epidermal necrolysis); Miscelianeous: hyperglycemia, glycosuria, hyperuricemia, muscle spasm, weakness, restlessness. Clinical trials of
TENORETIC conducted in the United States (89 patients treated with TENORETIC) revealed no new or unexpected adverse effects.

Potential Adverse Effects: In addition, a variety of adverse effects not observed in clinical trials with atenolol but reported with other beta-adrenergic blocking agents, should be considered potentis adverse ellects of atenolol. Nervous Systern. reversible mental depression progressing to catatoni short-term memory loss, emotional lability, slightly clouded sensorium, decreased performance on short-term memory loss, emotional lability, slightly clouded sensorium, decreased performance Gastrointestinal; mesenteric arterial thrombosis, ischemic colitis: Hematologic: agranulocylosis, nonthrombocytopenic purpura thrombocytopenic purpura; Allergic: erythematous rash, fever combined with aching and sore throat, laryngospasm and respiratory distress: Miscellaneous: reversible alopecia, Peyronie's disease.

There have been reports of a syndrome comprising psoriasilorm skin rash, conjunctivitis sicca. otitis, and sclerosing serositis attributed to the beta-adrenergic receptor blocking agent, practolol. This syndrome has not been reported with TENORETIC or TENORMIN (atenolol).

Clinica: Laboratory Test Findings: Clinically important changes in standard laboratory parameters were rarely associated with the administration of TENORETIC. The changes in laboratory parameters were not progressive and usually were not associated with clinical manilesta most common changes were increases in uric acid and decreases in serum potassium. Dostimal response is not achieved, the dosage should be increased to one TENORETIC 100 tablet once a day. Package insert should be consulted for dosage adjustments in cases of severe impairment of renal function.

impairment of renal function.
HOW SUPPLIED: TENORETIC 50 Tablets (atenolol $50 \mathrm{mg}$ and chlorthalidone $25 \mathrm{mg}$ ). NDC 0038-0115 (white, round, biconvex, uncoated tablets with TENORETIC 50 on one side and Stuart 115 on the (White, round, biconvex, uncoated tablets with TENORETE 50 on one side and Stuart 115 on the chlorthalidone $25 \mathrm{mg}$ ). NDC $0038-0117$ (white, round, biconvex, uncoated tablets with TENORETIC 100 on one side and Stuart 117 on the other side) are supplied in bottles of 100 tablets.

Protect from heat, light, and moisture. Dispense in well-closed, light-resistant container.

Inactive ingredients: magnesium stearate, microcrystalline cellulose, povidone, sodium starch glycolate. 


\section{CERTIFICATION OF HOME STUDY}

This is to certify that I, activity for AOA CME credits.

Please print

completed the following

Type of activity (such as reading or listening)

Name of journal(s) or audio-tape and date(s) of issue(s):

(One-half CREDIT may be granted for each issue or tape)

MAIL TO: AOA Division of CME, 212 East Ohio Street, Chicago, Illinois 60611 KEEP A DUPLICATE FOR YOUR RECORDS!

The Home Study form is intended to document individual reading of recognized scientific journals, listening to approved audio-tapes, and other approved home study courses and programs under the criteria described for Category 2-B.

Only one type of home study, such as reading, should be indicated on a single form, though multiple issues of scientific journals may be listed.

This form should not be used, however, when CME quiz cards for the AOA Journal are submitted separately.

\begin{tabular}{|l|}
\hline FOR OFFICE USE ONLY \\
\hline Date $\longrightarrow$ Credits \\
Program \# $\#$ \\
Doctor \# \\
Doctor's Name \\
\hline
\end{tabular}

Please refer to the revised CME GUIDE for additional information. 
MOVING?

Don't

Forget Us

Attach current mailing label, print your new address, and mail this form to:

Circulation Department

American Osteopathic

Association

142 E. Ontario St.

Chicago, Illinois 60611

Please allow 4-6 weeks for delivery.

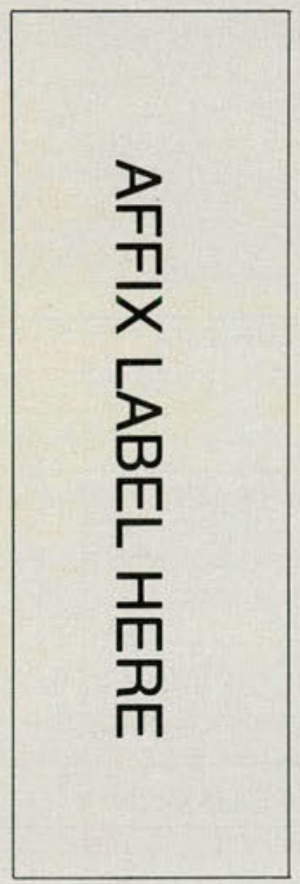

NEW ADDRESS:

\section{Name}

\section{AOA Number}

\section{Address}

City State Zip

\section{advertisers' index}

Key Pharmaceuticals

Nitro-Dur II, 24-26

Lever Brothers, Inc.

Dove Bar, Cover 3

Lilly \& Company, Eli

Ceclor, 4

Merck Sharp \& Dohme

Clinoril, 10-12

Vaseretic, $51-55$

Merrell Dow Pharmaceutical, Inc.

Institutional, 3

Lorelco, 63-66

Seldane, $17-20$

Muro Pharmaceutical Inc.

Bromfed, 61,62

Pfizer Laboratories

Feldene, 29, 30

Procardia, 6-7

Roche Laboratories

Medical Director's Page, 13

Roche Products Inc.

Valium, 44, 45

Roerig

Glucotrol, 56-58

Ross Laboratories

Similac, 22

Schein Inc., Henry, 27

Smith Kline \& French Laboratories Tagamet, Cover 4

Squibb \& Sons, Inc., E.R. Capozide, 83-86

American Osteopathic Association Convention Registration

Form, 77, 78

Hotel Convention Registration

Form, 49, 50

Beecham Laboratories

Fastin, 32-34

Gerber Products Company, 35
Stuart Pharmaceuticals

Tenoretic, 114-118

Syntex Laboratories, Inc. Anaprox, 47, 48

Upjohn Company Medrol, 15

Micronase, 39, 40, 103, 104

Motrin, 59

Xanax, Cover 2-2 

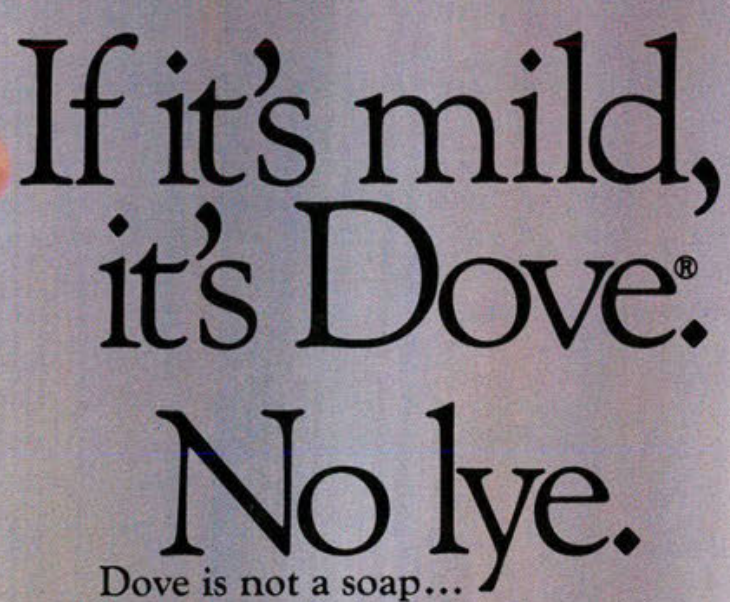

Dove is not a soap...
but a neutral cleansing bar with $1 / 4$ moisturizing cream.

All soaps are made with lye. That's what makes soap alkaline by definition. Even with the addition of various emollients, soaps remain decidedly alkaline-in the region of $\mathrm{pH}$ 10. And this level of alkalinity can damage the skin's protective acid mantle.

DOVE, on the other hand, does not strain the skin's natural buffering capacity. With a neutral $\mathrm{pH}$ of 7 , DOVE cannot strip away the skin's moisture-producing oils the way soaps do. Instead, DOVE works to retain needed moisture... leaving the skin soft, moist, and healthy-looking.

Any wonder that more physicians recommend DOVE than any other cleansing product? 


\section{Your ulcer patients where}

hepatotoxicity is a special concern:

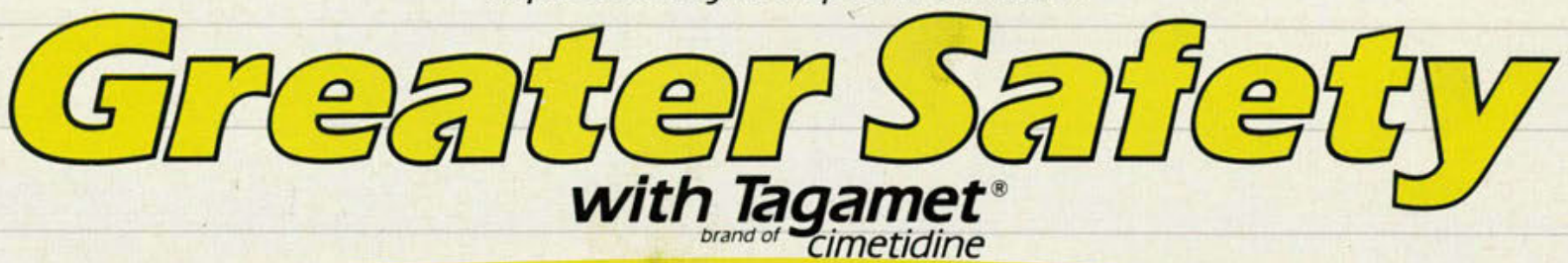

\section{Lower risk of hepatotoxicity than Zantac ${ }^{\circ *}$}

A 1985 review of the literature summarized a number of cases of 'Zantac' hepatotoxicity, including two positive rechallenges.' Furthermore, in a retrospective analysis of hepatotoxicity data, there were fewer reports

of hepatotoxicity with 'Tagamet' than with 'Zantac'?

And unlike 'Zantac,' 'Tagamet' does not potentiate acetaminophen hepatotoxicity, ${ }^{3.4}$ and has been shown to inhibit the formation of toxic acetaminophen metabolites. $3.5,6$

For a complete description of the side effects, potential drug interactions, and other precautions, please see brief summary below.

Before prescribing, see complete prescribing information in SK\&F LAB CO. literature or PDR. The following is a brief summary.

Contraindications: There are no known contraindications to the use of 'Tagamet'

Precautions: While a weak antiandrogenic effect has been demonstrated in animals, 'Tagamet' has been shown to have no effect on spermatogenesis, sperm count, motlihy. morphology or in vitro fertilizing capacily in humans.

In a 24-month toxicily study in rats at dose levels approximately 9 to 56 times the recommended human dose, benign Leydig cell tumors were seen. These were common in both the treated and control groups, and the incidence became significantly higher only in the aged rats receiving 'Tagamer'.

Rare instances of cardiac arrtythmias and hypotension have been reported following the rapid administra tion of 'Tagamet' $\mathrm{HCl}$ (brand of cimetidine hydrochloride) Injection by intravenous bolus.

Symptomatic nesponse to 'Tagamet' therapy does not preclude the presence of a gastric malignancy There have been rare reports of transient healing of gastric uicers despite subsequently documented malignancy. Reversible confusional states have been reported on occasion, predominantly in severely ill pabients. 'Tagamet' has been reported to reduce the hepatic metabolism of wartarin-type anticoagulants, phenytoin. propranolol, chlordiazepoxide, diazepam, lidocaine, theophyline and metronidazole. Clinically significant effects have been reported with the wartarin anticoagulants, therefore, close monitoring of prothrombin fime is recommended, and adjustment of the anticoagulant dose may be necessary when 'Tagamet' is administered concomitantly. Interaction with phenytoin, lidocaine and theophylline has also been reported to produce adverse clinical effects.

However, a crossover study in healthy subjects receiving eilher 'Tagamer $300 \mathrm{mg}$. q.1. or $800 \mathrm{mg}$. h.s. concomitantly with a $300 \mathrm{mg}$ b.i.d. dosage of theophyline (Theo-Dur", Key Pharmaceuticals, Inc.).

1. Physicians' Drug Alert 1985, VI/8). 2. Souza Lima MA: Ann Intern Med 1986

105: 140. 3. Jackson JE: Life Sci 1982:31:31-35. 4. Black M: Phila Med 1986;82:230-237

5. Leonard TB, Morgan DG, Dent JG. Hepatology 1985:5:480-487. 6. Mitchell MC

schenker S, Speeg KV: J Clin Invest 1984,73:383-391.

*ranitidine HCl, Glaxo Inc demonstrated less alteration in steady-state theophylline peak serum levels with the $800 \mathrm{mg}$. h.s. regimen, particularly in subjects aged 54 years and older Data beyond ten days are not available. Note: All patents receiving theophylline should be monitored appropriately, regardless of concomitant drug therapy). Lack of experience to date precludes recommending 'Tagamet' for use in pregnant patients, women of risks; generally, nursing should not be undertaken in patients taking the drug since cimetidine is secreted in human mik.

Adverse Reactions: Diarthea, dizziness, somnolence, headache, rash. Reversible arthralgia, myalgi and exacerbation of joint symptoms in patients with preexisting arthnitis have been reported. Reversib. disorientation), predominantly in severely ill patients, have been reported. Gynecomastia and reversible impotence in patients with pathological hypersecretory disorders receiving 'Tagamet', particularly in high impolence in patients will pathological hypersecretory disorders receiving lagamer, particulanily in high ares, Decreased whice blood cell counts in lagamet frealed patients approximatery 1 per 100,000 patients). including agranulocylosis (approximarey J per milion patients, have been reporled, including a lew reports

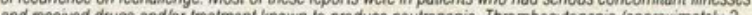
a per minon patenss and a lew cases of aplasuic anemia have aso been repor ted. increased serum trans. aminase and creatinine, as weil as rare cases of tever, interstitia nephritis, uninary refention, pancreaturis and allegic reactions, hcludig hypersensichly vascuits, have been reported. heversible adverse hepalic ellecks, cholestabc or mided cholestalic hepalocesilar in nature, have been reported rarej. Because of the predominance of cholestautc leatures, severe parenchymal injury is considered highy unikely. A single case ing Tagamet has been reported BRS:TG:L73A

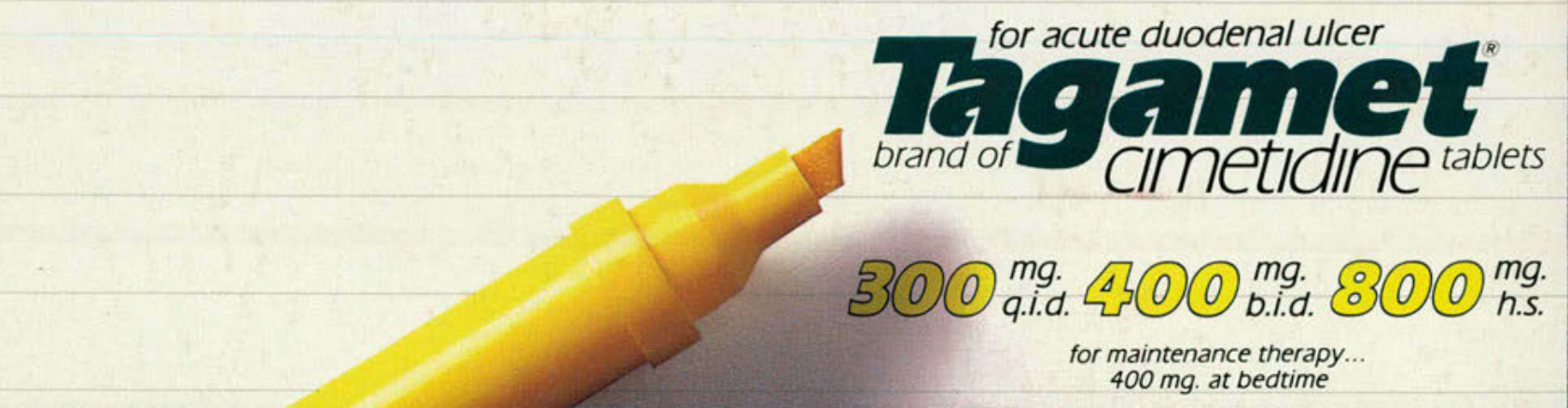

